\title{
A Review about Futsal
}

\author{
Daniel Berdejo-del-Fresno* \\ The Football Association, Sheffield FC Futsal \\ *Corresponding author: daniberdejo@gmail.com
}

Futsal is the format of small sided football that is recognised and supported by FIFA and UEFA with World and African, Asian, American (North and Central and South), Oceanian and European Championships for Club and National Teams.

The name "Futsal" simply combines the Spanish words for "Hall" - Sala and "Football" - Fútbol into futsal. It is a five-a-side game, played with hockey sized goals and a smaller ball with a reduced bounce. Futsal was developed in Brasil and Uruguay in the 1930s and 1940s as a solution to the lack of available football fields. Since the beginnings futsal has been very popular in South America, Portugal, Spain and Italy. In the last decade, futsal has increased a lot in Asian countries such as Iran, Japan, Kuwait...

Futsal is also the World's fastest growing indoor sport. In fact, nowadays there are plenty of talks in the media and social media to try to push the International Olympic Committee to decide if futsal becomes an Olympic Sport or even a Winter Olympic Sport.

However, there is a lack of scientific papers about futsal in English language. Only a couple of authors (one Spanish and one Italian) have published some few futsal articles in English. On the contrary, there are hundreds of papers, articles and documents about futsal written in Portuguese, Spanish or Italian. This fact is not helping to develop futsal in the right way, as many international coaches, S\&C coaches, sport scientists, physiotherapists, doctors cannot understand those languages. Therefore, if we want to develop futsal as a professional sport, we need to be able to increase the level in futsal in all the fields. The only way to get that objective is trying to get as many as possible articles in English language, since that language is the international one.

It is there, when the American Journal of Sports Science and Medicine came. When they offered me to be the Guest Chief Editor for a special issue I did not hesitate a second, I knew it. I wanted to do it about this lovely sport called FUTSAL. The moment has arrived, the special issue is published. It gives me great pleasure to welcome you to the first special issue of the AJSSM. This issue is the largest issue of the AJSSM to date and includes contributions from a range of professionals and academics from the UK, Europe and Asia. The first article of this issue covers the analysis of the conducts of futsal golakeepers in the different situations during the game.
There are two studies concerned with the hydration of futsal players. One in relation to the hydration habits of outfield futsal players during official matches in the Spanish professional first divison futsal league; the other studies the recovery and regeneration behaviours and hydration status of international futsal players during a training camp with the national team. A really interesting paper based on a Spanish PhD Thesis that studied the loss of entertainment in futsal after the new rules imposed by FIFA in 2006 is also presented. A 12-year case study analysing the heart rate variations in an elite futsal player competiting at the top level in Spain is covered in the fourth paper of this issue. Two studies investigated futsal referees. The first one, their fitness level; while the second one is a pilot study about the physiological demands (heart rate, core temperature, blood lactate and hydration status) of futsal referees in international matches. Then, a systematic review of futsal literature draws on diverse subjects including coaching, physiological, psychological, technical and tactical elements of the sport. The final paper assesses the futsal participation in England, where the sport is growing up a lot in the last years. The diversity of the articles presented in this special issue as well as their origin further highlights the great amount of professionals that are working in and for this fantastic sport, while its volume is an indication of the futsal popularity and development. The articles of this futsal special issue cover aspects of outfield players, goalkeepers, referees, futsal participation data, and the consequences of the change of the laws of the game in 2006. However, there is a gap that we could not close. In spite of the Editorial Team tried their best, we could not get just a single paper about any female aspect of the game (i.e. players, referees, participation...). Maybe this is a faithfully reflection about the reality of the sport, and maybe the female aspects of the game are the key factors that we should close to achieve the Olympic status that futsal deserves.

Finally, I would like to acknowledge to the American Journal of Sports Science and Medicine the opportunity that they gave me to manage and coordinate this special issue; and especially to my two Guest Editors and friends: Dr. Amador J. Lara-Sánchez (University of Jaén, Spain) and Dr. Antonio Tessitore (University of Rome "Foro Italico”, Italy). 